MATEC Web of Conferences 49, 05003 (2016)

DOI: $10.1051 /$ matecconf/20164905003

C Owned by the authors, published by EDP Sciences, 2016

\title{
The Response of Tree-Ring Growth to Climate at Upper Timberline of Southern Aspect of Mt. Taibai
}

\author{
QIN Jin, BAI Hongying ${ }^{a}$, SU Kai, LI Shuheng, WANG Jun \\ College of urban and environment science, Northwest University, X'an 710127, China
}

\begin{abstract}
In recent years, the impact of climate change on vegetation in Qinling mountainous area has already been authenticated by numerous investigations, nevertheless, as the major ridge of Qinling Mountains as well as national natural conservation reserve, the ecology response of Mt. Taibai sub-alpine vegetation to climate change has not yet gained enough public attention.In this study, in accordance with the method of dendrochronology, response analysis was carried out to contrast characteristic parameters of tree-ring width chronologies for Larix chinensis from different elevations as well as their response pattern to climate change. The result showed that, Mean sensitivity, standard deviation and variance in first eigenvector are increasing with the rise of elevation, but the correlation coefficients (R1, R2, R3) were decreasing which indicated that the strength of the tree's common or relative response to environment was decreasing with altitude. Precipitation had stronger correlation with the tree-ring radial growth than air temperature in both of the sites, during the growing season, trees in lower altitude had better correlation with temperature than in higher altitude, thus showing the different response to climate between the two different sites.
\end{abstract}

\section{Introduction}

Tree-ring dating, also known as dendrochronology has been an important climate investigation method all over the world during the past century, climatologists regard it as a promising means to study the climate change in the past due to its high resolution of time and precise dating method [1]

Through analyzing the tree-ring data could help us to understand climate behaviors and its background mechanisms in the specific region and predict the future [2-6]. In the extreme environments between the high mountains and sub-arctic zones, the climate of the forest margin is the main limiting factor of tree growth [7], nevertheless, previous research has shown that the relationship between tree-ring width and climate is complex $[8,9]$.

Qinling mountains, as the demarcation line of northern and southern China, mainly lies in the middle of Shaanxi province, northwest China. The Larix chinensis in the southern slope of its main peak Taibai mountain conveyed relatively clear signals of the climate change, they are vulnerable and sensitive if the climate continues to change because they can grow healthily only under specific conditions. As a result, studies in this region to obtain response variation information of the tree-width to climate is becoming more critical.Wealth of information was included in the samples of Larix chinesis located in the upper slope position and forest margin, so samples in these areas were suitable for doing analysis of annual rings ${ }^{[10]}$ and a 30 to 40 years cycle was found in temperature changes in the region [11], furthermore,treering width chronology has been built from Larix chinensis at the divide sampling site in the mid-Qinling Mountains from 1814 to 2003 [12]. However, different elevations in this area had a subsequent various consequences on the tree-ring width and the radial growth of the plant,the terrain and local climate characteristics of Qinling Mountains is complicated and changeable,most studies were targeted at the northern aspect of Mt.Taibai,but the relationship between tree growths and climate at the southern aspect around the forest margin is still unknown, further investigation is required.

In this paper, the two sample sites of the tree coresare close to each other $(3100 \mathrm{~m}, 3200 \mathrm{~m})$ so the distinctions of the response to climate under such a situation are what we mainly care about.

\section{Materials and methods}

\subsection{Site description and tree-ring material}

The tree samples were collected in the southeastern slope of Taibai Mountain around the forest margin in summer of 2012. It is located at the middle western part $\left(\mathrm{N} 33^{\circ} 49^{\prime} \sim 34^{\circ} 10^{\prime}\right.$,E $107^{\circ} 19^{\prime} \sim 107^{\circ} 58^{\prime}$ ) of the whole Qinling Mountains, also, on the edge of the subtropical monsoon climate area which has a huge barrier function on the warm air from the south in summer and the cold air from the north in winter. The habitat of Larix chinensis only covered the elevation at thee range of

\footnotetext{
a Corresponding author: Hongyingbai@163.com
} 
2600-3500m,the annual mean temperature of this height is $-2{ }^{\circ} \mathrm{C} \sim-1{ }^{\circ} \mathrm{C}$, annual total precipitation is about 800 900 mm.(Figure 1)

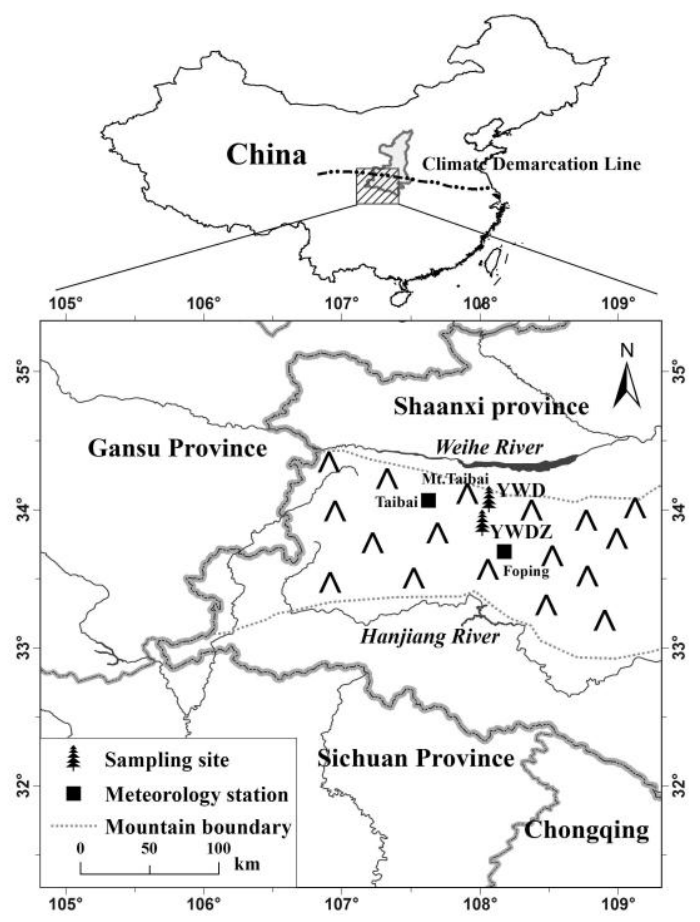

Figure 1. The major characteristics of the trees in two sample site

According to the ITRDB standard, increment cores were collected from 30 living trees in 2 individual $20 \mathrm{~m} \times 20 \mathrm{~m}$ plots, choose 15 trees per site at the height of $1.3 \mathrm{~m}(\mathrm{DBH})$ for extraction, named as YWD (upper) and YWDZ (lower) 2 cores per tree were perpendicularly extracted with the blue Sweden increment borer. The major characteristics of the two sites are listed in Table 1.It is obvious that the trees in YWDZ had a better living condition than YWD in all aspects given.

Table 1. The major characteristics of the trees in two sample sites

\begin{tabular}{|c|c|c|c|}
\hline $\begin{array}{c}\text { Sample } \\
\text { site }\end{array}$ & $\begin{array}{c}\text { range of } \\
\text { height }(\mathbf{m})\end{array}$ & $\begin{array}{c}\text { range of } \\
\text { diameter(cm) }\end{array}$ & $\begin{array}{c}\text { range of crown } \\
\text { density(\%) }\end{array}$ \\
\hline YWD & $6-15$ & $18.15-31.21$ & $30-65$ \\
\hline YWDZ & $13-20$ & $22.92-38.69$ & $70-75$ \\
\hline
\end{tabular}

Tree-ring samples were treated following standard practices [13]. All cores were dried, glued, fixed and mounted. After cross-dating, each individual ring was identified with an accurate calendar year, and then each annual ring width was measured within $0.01 \mathrm{~mm}$ by manipulating the professional facility LINTAB 5. The quality control of cross-dating was operated by using COFECHA program [14]. Some of the samples found to be significantly hard to cross-date were abandoned from the development of the chronologies, general information of the sample sites is summarized in Table 2.
Table 2. The general condition of the sample site

\begin{tabular}{|l|c|c|c|c|c|}
\hline Sample site & $\begin{array}{c}\text { North } \\
\text { longitude }\end{array}$ & $\begin{array}{c}\text { East } \\
\text { latitude }\end{array}$ & Elevation & $\begin{array}{c}\text { Sample } \\
\text { cores }\end{array}$ & Length \\
\hline YWDZ1 & $107^{\circ} 46^{\prime} 43^{\prime \prime}$ & $33^{\circ} 59^{\prime} 3^{\prime \prime}$ & 3107 & 10 & 100 \\
\hline YWDZ2 & $107^{\circ} 46^{\prime} 44^{\prime \prime}$ & $33^{\circ} 55^{\prime} 8^{\prime \prime}$ & 3093 & 10 & 116 \\
\hline YWDZ3 & $107^{\circ} 46^{\prime} 45^{\prime \prime}$ & $33^{\circ} 56^{\prime}$ & 3122 & 10 & 95 \\
\hline YWD1 & $107^{\circ} 46^{\prime} 47^{\prime \prime}$ & $33^{\circ} 56^{\prime}$ & 3200 & 10 & 100 \\
\hline YWD2 & $107^{\circ} 46^{\prime} 7.5^{\prime \prime}$ & $33^{\circ} 56^{\prime} 1^{\prime \prime}$ & 3213 & 10 & 155 \\
\hline YWD3 & $107^{\circ} 46^{\prime} 6.6^{\prime \prime}$ & $33^{\circ} 56^{\prime} 1^{\prime \prime}$ & 3212 & 10 & 259 \\
\hline
\end{tabular}

\subsection{Chronology development}

The individual ring-width measurement series were double detrended and standardized to ring-width indices by using the ARSTAN program [15]. Undesirable growth trends, related to age and stand dynamics but unrelated to climatic variations, were removed from each series during the detrending process. To conserve the maximum common signal at the lowest frequency possible, each ring-width measurement series was standardized conservatively by fitting a negative exponential or straight line. All individual index series were combined into a single chronology by computing a bi-weight robust mean. In further analysis, the Residual version (RES) of the chro-nology was used since it provides relatively higher response signals and more high frequency signals than the STD chronology in our research. In additionn, a lot of works had been done in the past was using RES chronology for investigating the differences in responses to climate.

The statistical characteristics of the RES chronol-ogy in different elevations are listed in Table 3.

Table 3. Statistical features of the YWD and YWDZ residual chronologies

\begin{tabular}{|c|c|c|}
\hline Statistical item & YWD & YWDZ \\
\hline Mean sensitivity & 0.3043 & 0.2055 \\
\hline standard deviation & 0.2803 & 0.1841 \\
\hline $\begin{array}{c}\text { First order auto- } \\
\text { correlation }\end{array}$ & 0.0793 & 0.0128 \\
\hline $\begin{array}{c}\text { Variance in first } \\
\text { eigenvector(\%) }\end{array}$ & $55.70 \%$ & $54.99 \%$ \\
\hline Signal-to-noise ratio & 2.711 & 2.726 \\
\hline R1 & 0.493 & 0.509 \\
\hline R2 & 0.475 & 0.476 \\
\hline R3 & 0.537 & 0.594 \\
\hline
\end{tabular}

$\mathrm{R} 1$ is the average correlation coefficient between all cores, R2 is the correlation coefficient between different trees, R3 is the correlation coefficient between all samples from the same tree. 


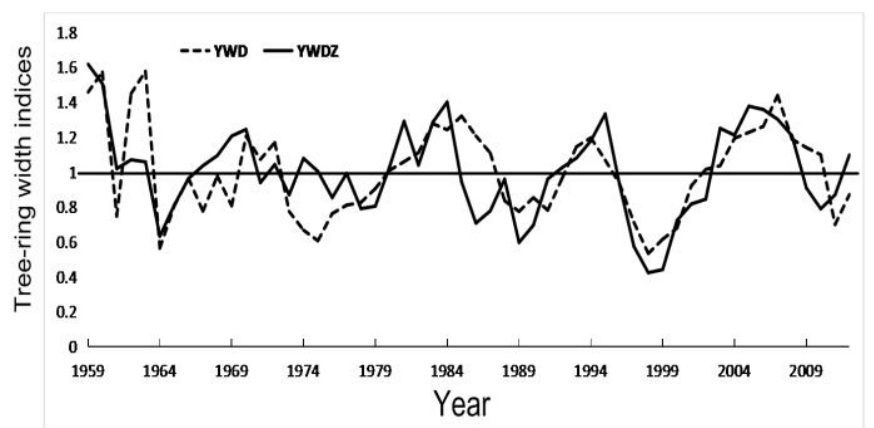

Figure 2. The curves of the RES chronologies of YWD and YWDZ in common interval.

The mean sensitivity (M. S.) and standard deviation (S. D.) of YWD is higher than YWDZ, which means the year-to-year variability of plant growth was increasing with elevation. In conclusion, the Larix chinensis from the site of YWD are more sensitive to climate than the samples from YWDZ.

The variance of the first eigenvalue (PC1) of each chronology, expressing the degree of common signals, also increases with altitude. Therefore, the consistency of the tree's response to climate are directly linked to altitude even if there is subtle level difference in elevation.

Nevertheless, the signal to noise ratio, also as SNR which is the ratio of climate signal to non-climate signal, is higher in YWDZ (2.726) than YWD (2.711) but they were almost the same and the correlation coefficients (R1, $\mathrm{R} 2, \mathrm{R} 3$ ) in RES chronology of both sites indicated that the the trees in YWD and YWDZ both contains high signal.Hence, both sites are suitable for dendrochronology study.

We can infer from the curves of the public interval RES chronologies from the YWD and YWDZ in their common interval (Figure 2) that the chronologies have very similar variations, such as the dumps during 1913, 1963 and 1998, the humps during 1930 and 1945, since they were extracted from the same climate region. In other words, similar variations in the chronologies suggest the tree-ring width at different elevations is affected by similar climate factors.

\subsection{Meteorological data}

In order to understand the varied response of trees to climate at such different elevations and find which climate factor is the main one responsible for the difference, the correlation between the 2 chronologies to both precipitation and temperature in different months was calculated.

The meteorological data used in this analysis are from the Taibai weather station and Foping weather station since 1959 (Figure 3). The Taibai station lies in the northwestern side of the sample sites and the Foping station lies in the southern side of the sample sites, their major information is summarized in Table 4, they are both close to the sample sites and located in the same climate region (Table 4), so we calculated the annual meann temperature and annual mean precipitation of the two stations in different months for analysis.

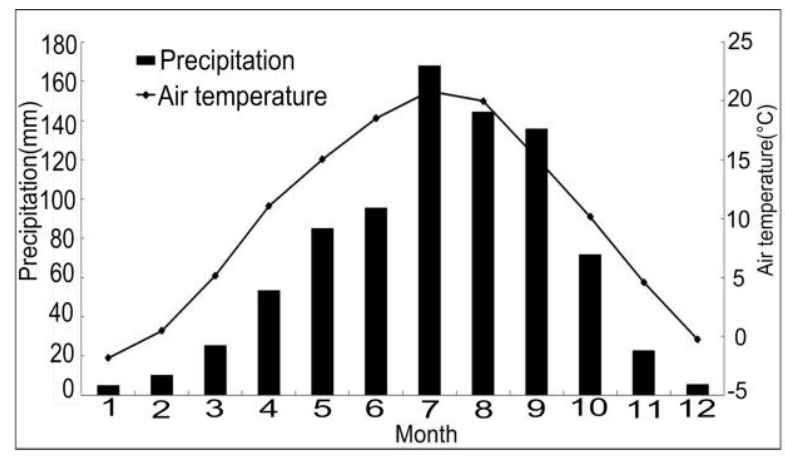

Figure 3. Calculated monthly mean air temperature and precipitation of the Taibai and Foping station

Table 4. The information about the meteorological stations

\begin{tabular}{|c|c|c|c|}
\hline Stations & Elevation & North longitude & East latitude \\
\hline Taibai & 1543 & $34^{\circ} 5^{\prime} 24^{\prime \prime}$ & $107^{\circ} 17^{\prime} 59^{\prime \prime}$ \\
\hline Foping & 1087 & $33^{\circ} 32^{\prime} 59^{\prime \prime}$ & $108^{\circ} 0^{\prime} 0^{\prime \prime}$ \\
\hline
\end{tabular}

It is conspicuous that the air temperature and the precipitation in this area were increasing and dropping at the same period which is related to characteristics the temperate monsoon climate, the temperature and precipitation reached their peak in July. (Figure 3).

\section{Results and discussion}

It is critical to measure if the chronology could reflect the climate signal or not by doing correlation analysis between the chronology and the meteorological data when doing climate research with tree-ring width [16]. To calculate the correlations between the 2RES chronologies and the meteorological data since 1959 and find the divergence of their response to climate, we choose Dendroclim 2002 and SPSS as the software for statistical analysis..Because of the lagging effect, we select the mean monthly precipitation and mean monthly air temperature from October of previous year to October of current year for study (Figure 4, Figure 5).

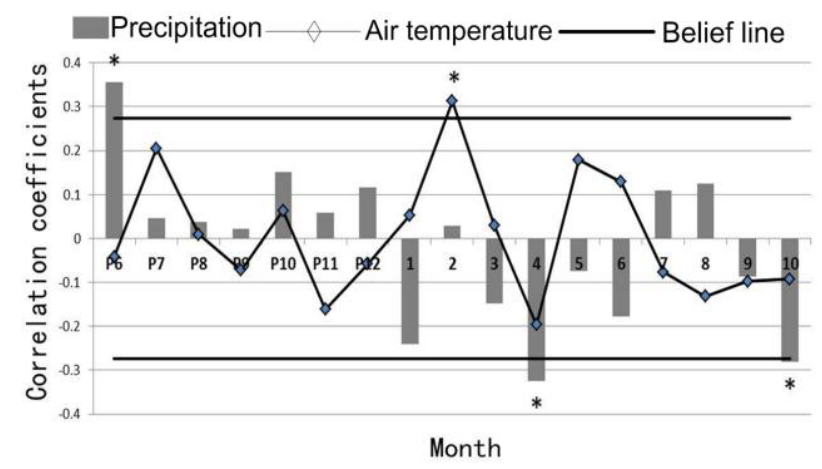

Figure 4. Response function analysis for the relationship between RES chronology of and climate factors in YWD 


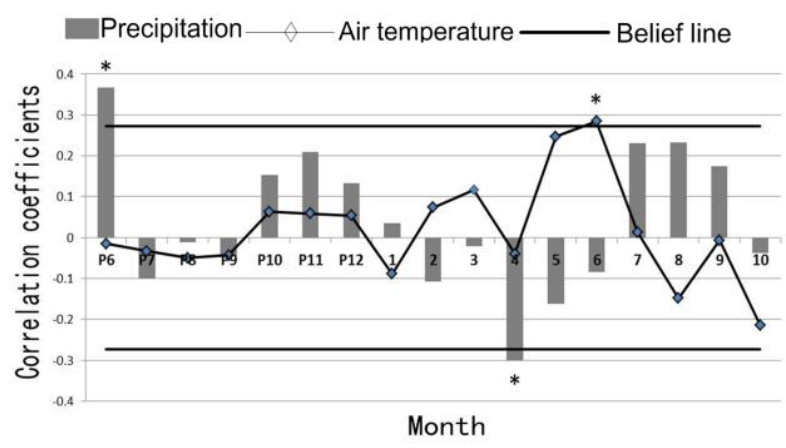

Figure 5. Response function analysis for the relationship between RES chronology of tree-ring width indices and climate factors in YWDZ

\subsection{Common characters}

It is obvious that the two graphs reflected some similar characteristics.

To precipitation, both of the two sites' tree-ring widths had notable positive correlation with precipitation in June of previous year, it means the precipitation in previous year had stronger positive effect on the radial growth of the trees even to current year, this phenomenon is directly linked to the "lagging effect", which proved that the Larix chinensis had notable "lagging effect" with precipitation; Another conspicuous resemble character is that the tree-ring width of the two sites all respond notably positively to precipitation in April in current year, this may due to the special environmental condition at that time, during the days in April the ice of the mountains began to melt, the trees had enough water for grow but not enough temperature and light, more precipitation could limit the time of sunlight and warmth then turned out to be the significantly slowing down the speed of tree-ring radial growth.

In summer, from April to July better condition of temperature can help to increase the speed of photosynthesis, in August when temperature began to fall and the grow season is at the end of the corner, high temperature would cause higher evaporation then it has negative correlation with the temperature again.

In conclusion, it can be inferred from the data and graphs that the precipitation had stronger correlation with the radial growth than air temperature in both of the sites, this proved them to be in the same climate region. However, there still exists some significant differences in correlation strength between the two chronologies.

\subsection{Different characteristics}

Despite the similarities in the two chronologies, there are some distinctions can't be ignored.

After comparison of the two sample sites in Table 1, we can tell that the total living status in YWDZ is better than YWD, his can be described as the result of elevation, the higher the elevation is , the worse environment it will be.

It can be revealed from Figure 4 and Figure 5 that YWD had significant positive correlation with temperature in February, because in spring when temperature began to rise, YWD had better water supply than YWDZ for it is close to the peak, higher temperature can make the ice melting faster, and initially absorbed by the trees in YWD which promoted the radial growth.

In winter during October, the precipitation had notable negative correlation with tree-ring width in YWD, at that time the growth season is over, the precipitation could bring cold water which is a limitation in radial growth and the photosynthesis would also be influenced under such low temperature, the temperature in YWD is relatively colder than YWDZ, as a result, YWD had rather significant negative correlation with precipitation than YWDZ at that time. There is a remarkable peak in temperature in the Fig. 5 showed that in the growth season in YWDZ had very good correlation with temperature than YWD, this can be explained as the YWD' s air temperature is always lower than YWDZ, in growing season of June the temperature in YWDZ is more suitable for radial growth than the trees in YWD.

\section{Conclusions}

(1) The living condition of the Larix chinensis in YWDZ is better than YWD, in other words, the Larix Chinensis in YWDZ are healthier than YWD, the environment in YWDZ are more suitable for the Larix Chinensis to habitat.

(2) Values of statistical features of the YWD and YWDZ residual chronologies are high enough for dendrochronology study, while the chronology of YWD contains more information of environment change than YWDZ.

(3) The precipitation had stronger correlation with the radial growth than air temperature in both of the sites, most importantly, precipitation in June of previous year had significant lagging effect with width indices, that is to say, precipitation is the limiting factor of the radial growth for both of the sites. In the growing season in YWDZ had very good correlation with temperature than YWD.Their significant differences had physiological meaning.

However,the work of climate reconstruction during the last 100 years between the two sites at Mt.Taibai haven't been done yet ,in order to have a better understanding of the climate change around this elevation and explain why the Abies fargesii at the timberline could response differently to climate change.Our next study will put an emphasis on climate reconstruction in this region to figure out the historical reasons for the phenomenon found above.

\section{Acknowledgments}

We would like to thank Dr. Bao guang from Baoji university of arts and sciences and Dr.Li gang from Northwest university for their great help in this article.

\section{References}

1. Fritts, H. C. (eds), London: Academic Press, (1976) 
2. Briffa, K. R., Jones, P. D., Schweigruber, F. H., Osborn, T. J., Nat., 393, 450-454 (1998)

3. Frank, D., Wilson, R., Esper, J., Boreas, 34, 498-505 (2005)

4. Rutherford, S., Mann, M. E., Osborn, T. J., Bradley, R. S., Briffa, K. R., Hughes, M. K., Jones. P. D., Journal of Climate, 18, 2308-2329 (2005)

5. Esper, J., Frank, D., Büntgen, U., Verstege, A., Luterbacher, J., Xoplaki, E., Geophysical Research Letters, DOI:10.1029/2007GL030844 (2007)

6. Mann, M. E., Zhang, Z. H., Hughes, M. K., Bradley, R. S., Miller, S. K., Rutherford, S., Ni, F. B., Proceedings of the National Academy of Sciences of the United States of America, 105, 13, 252-13, 257 (2008)

7. Tessier, L., Guibal, F., Schweingruber, F. H., Climatic Change, 36, 499-517 (1997)

8. Buckley, B. M., Cook, E. R., Peterson, M. J., Barbetti, M., Australia. Climatic Change, 36, 477498 (1997)
9. Splechtna, B. E., Dobry, J., Klinka, K., Annals of Forest Science, 57, 89-100 (2000)

10. Kang, Y. X., Liu, J. H. Dai, S. F., He, X. J., Journey of northwest university of A\&F (Nature science edition), 38, 12, 141-147 (2010)

11. Dai, J. H., Shao, X. M., Cui, H. T., Ge, Q. S., Liu, H. Y., Tang, Z. R., Quaternary Science. 23, 428-435 (in Chinese with English abstract) (2003)

12. Liu, Y., Liu, N., Song, H. M., Cai, Q. F., Bao, G., Wang, W. P, Advances In Climate Change Research, 5, 5, 260-265 (2009)

13. Stokes, M. A., Smiley, T. L., The University of Arizona Press, Tucson (1996)

14. Holmes, R. L., Tree-ring Bulletin 43, 69-78 (1983)

15. Cook, E. R., D, University of Arizona, Tucson (1985)

16. Fritts, H. C., The University of Arizona Press, Tucson, USA (1991) 